\title{
Select cognitive deficits in Vasoactive Intestinal Peptide deficient
} mice

\author{
Dipesh Chaudhury ${ }^{1,2}$, Dawn H Loh ${ }^{1}$, Joanna M Dragich ${ }^{1}$, Arkady Hagopian ${ }^{1}$ \\ and Christopher S Colwell*1
}

Address: ${ }^{1}$ Department of Psychiatry and Biobehavioral Sciences, University of California - Los Angeles, 760 Westwood Plaza, Los Angeles, California 90024-1759, USA and 2Department of Neurobiology and Behavior, W257 Seeley G Mudd Bioscience Wing, Cornell University, Ithaca, New York, 14850, USA

Email: Dipesh Chaudhury - dc478@cornell.edu; Dawn H Loh - hloh@mednet.ucla.edu; Joanna M Dragich - jdragich@ucla.edu; Arkady Hagopian - arkhag@gmail.com; Christopher S Colwell* - ccolwell@mednet.ucla.edu

* Corresponding author

Published: 10 July 2008

BMC Neuroscience 2008, 9:63 doi:10.1/86/147|-2202-9-63
Received: 27 February 2008

Accepted: 10 July 2008

This article is available from: http://www.biomedcentral.com/I47I-2202/9/63

(C) 2008 Chaudhury et al; licensee BioMed Central Ltd.

This is an Open Access article distributed under the terms of the Creative Commons Attribution License (http://creativecommons.org/licenses/by/2.0), which permits unrestricted use, distribution, and reproduction in any medium, provided the original work is properly cited.

\begin{abstract}
Background: The neuropeptide vasoactive intestinal peptide (VIP) is widely distributed in the adult central nervous system where this peptide functions to regulate synaptic transmission and neural excitability. The expression of VIP and its receptors in brain regions implicated in learning and memory functions, including the hippocampus, cortex, and amygdala, raise the possibility that this peptide may function to modulate learned behaviors. Among other actions, the loss of VIP has a profound effect on circadian timing and may specifically influence the temporal regulation of learning and memory functions.

Results: In the present study, we utilized transgenic VIP-deficient mice and the contextual fear conditioning paradigm to explore the impact of the loss of this peptide on a learned behavior. We found that VIP-deficient mice exhibited normal shock-evoked freezing behavior and increases in corticosterone. Similarly, these mutant mice exhibited no deficits in the acquisition or recall of the fear-conditioned behavior when tested 24-hours after training. The VIP-deficient mice exhibited a significant reduction in recall when tested 48-hours or longer after training. Surprisingly, we found that the VIP-deficient mice continued to express circadian rhythms in the recall of the training even in those individual mice whose wheel running wheel activity was arrhythmic. One mechanistic explanation is suggested by the finding that daily rhythms in the expression of the clock gene Period2 continue in the hippocampus of VIP-deficient mice.
\end{abstract}

Conclusion: Together these data suggest that the neuropeptide VIP regulates the recall of at least one learned behavior but does not impact the circadian regulation of this behavior.

\section{Background}

The neuropeptide vasoactive intestinal peptide (VIP) is expressed in specific subpopulations of neurons in the central and peripheral nervous system. Two receptors, encoded by distinct genes, bind VIP with high affinity:
$\mathrm{VPAC}_{1} \mathrm{R}$ and $\mathrm{VPAC}_{2} \mathrm{R}$ [1-3]. VIP and its receptors are expressed in those brains regions thought to be involved in learned behaviors, including the hippocampus, cortex, amygdala and hypothalamus e.g. [4-6]. While the physiological actions of this neuropeptide have not been exten- 
sively studied, VIP regulates synaptic transmission [e.g. [7,8]] and intrinsic membrane currents [e.g. [9-12]]. Thus, this neuropeptide can be a potent modulator of neural activity and function in specific circuits in the adult nervous system.

Previous pharmacological studies have raised the possibility that VIP modulates learning and memory processes. The central administration of VIP causes marked impairment in passive avoidance and spatial memory [13-17]. Inhibition of VIP by use of antagonists also affects spatial learning [18]. Removal of VIP-producing cells by expression of a chimeric VIP-diptheria toxin gene caused learning deficits [19]. Furthermore, VIP agonists protect against the impaired spatial learning observed in experimental Alzheimer mouse models [20,21]. Mechanistically, VIP regulates the secretion and expression of neurotrophic factors [22-26] and VPAC receptors are potent activators of the adenylyl cyclase/protein kinase A cascade [27] that has been implicated in the regulation of long-term memory formation [e.g. $[28,29]]$. Interestingly, recent work found that treatment of pregnant mice with a VIP antagonist caused cognitive deficits in the male offspring and lead to the suggestion that these mice may serve as a model of autism [30]. Together, this literature is consistent with hypothesis that VIP signaling could regulate learned behavior in the adult.

There is strong evidence that VIP and the $\mathrm{VPAC}_{2} \mathrm{R}$ are critical for the normal functioning of the circadian system. Early studies on young rats showed breakdown in locomotor rhythms following application of VIP antagonists [31]. More recent studies come via the development of transgenic mice lacking VIP [32] or $\mathrm{VPAC}_{2} \mathrm{R}$ [33]. All of the VIP- and $\mathrm{VPAC}_{2} \mathrm{R}$-deficient mice exhibit disruptions in their ability to express a coherent circadian rhythm in constant conditions although the extent of the arrhythmic phenotype varies from animal to animal. At a cellular level, VIP- and $\mathrm{VPAC}_{2} \mathrm{R}$-deficient mice fail to exhibit the midday peak in electrical activity that is characteristic of impulse rhythms from suprachiasmatic nuclei (SCN) brain slices [34-36]. Together, these data indicate that VIP and $\mathrm{VPAC}_{2} \mathrm{R}$ are critical for the generation of behavioral rhythmicity in mice and that the deficit occurs at the level of the SCN. This data also serves to point out the utility of transgenic models in the exploration of the role of VIP in behavior.

In the present study, we used VIP-deficient mice to determine the role of this peptide in the regulation of contextual fear conditioning. We first determined whether VIPdeficient mice exhibited deficits in shock-evoked freezing behavior or corticosterone response. Next, we determined whether these mice exhibited deficits in acquisition or recall of contextual fear response. Furthermore, we exam- ined whether the loss of VIP influenced the daily and circadian rhythms in the recall of the conditioned fear response. Finally, we determined whether daily rhythms in the expression of the clock gene Period 2 could be measured in the hippocampus of VIP-deficient mice.

\section{Results}

Acute freezing behavior in WT and VIP-deficient mice

We first determined if VIP-deficient mice exhibited deficits in sensitivity to foot-shock by testing the direct shockevoked fear response at ZT3 (day). WT and VIP-deficient mice were exposed to shocks of a range of intensities $(0.1$ to $1 \mathrm{~mA}$, duration) and the freezing response measured (Fig. 1A). Overall, the freezing response to the shock were higher in the VIP-deficient mice (RM-ANOVA: $P<0.05$ ) compared to WT controls. The VIP-deficient mice exhibited significantly (t-test: $\mathrm{t}=3, P<0.01$ ) more freezing at the lowest intensity $(0.1 \mathrm{~mA})$. For the remainder of the study, we used the lowest intensity of shock $(0.2 \mathrm{~mA})$ that did not produce any significant differences between the genotypes. Thus, the VIP-deficient mice do not exhibit defects in shock-evoked freezing behavior.

\section{Acute corticosterone response in WT and VIP-deficient mice}

The concentration of circulating corticosterone is actively regulated as part of the stress response exhibited by mice. We sought to determine whether the endocrine response to foot-shock $(0.2 \mathrm{~mA})$ was altered in VIP-deficient mice. For these experiments, we examined corticosterone response to a mild foot-shock in WT and VIP-deficient mice in early day (ZT 3, $n=3$ per group). WT mice subjected to foot-shock exhibited significantly higher concentrations (t-test: $\mathrm{t}=-4.0, P<0.05)$ of serum corticosterone than unstressed mice (Fig. 1B), and VIP-deficient mice showed a similar increase in corticosterone concentration upon exposure to acute stress (t-test: $\mathrm{t}=-3.3, P<0.05$ ). There were no significant differences in the baseline or stress-evoked serum corticosterone concentrations between WT and VIP-deficient mice, suggesting the induction of corticosterone in response to stress is intact in VIPdeficient mice.

\section{Acquisition in VIP KO mice following contextual fear training}

Given that VIP is expressed in brain regions implicated in learning, including the hippocampus, we sought to determine if learning was altered in VIP-deficient mice. For these experiments, we examined the acquisition of contextual fear conditioning in WT and VIP-deficient mice at ZT 3 using 2 CS-US pairing with $0.2 \mathrm{~mA}$ shock $(n=8$ per group). Both WT and VIP-deficient mice learned the task (Fig. 2) and there were no significant differences in the acquisition between the two genotypes (t-test: CS-US-1: $t$ $=0.5, P=0.63$; CS-US- $2: \mathrm{t}=-0.4, P=0.73)$. With a second 

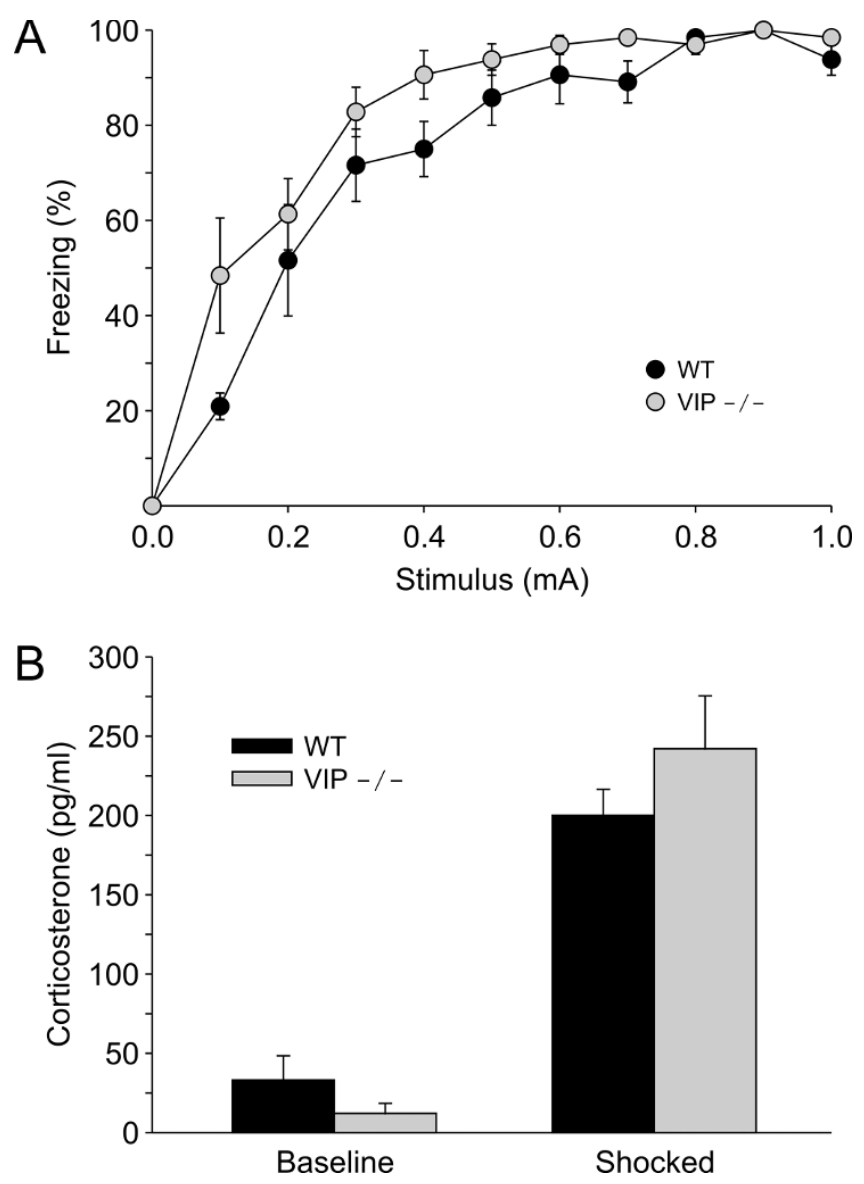

Figure I

The loss of VIP does not impact shock-evoked freezing or corticosterone response. A) WT and VIP-deficient mice were directly shocked with progressively increasing stimulus intensities and the freezing response measured. The measurement of these acute fear responses were conducted in the early day (ZT 3). The VIP-deficient mice exhibited more freezing in response to the lowest intensity shock $(0.1 \mathrm{~mA})$ but there were no differences between the genotypes at the other shock intensities. B) Corticosterone response to acute stress evoked by footshock (0.2 mA applied twice) in the early day (ZT3). Both WT and VIP-deficient mice displayed a significant induction of corticosterone in response to acute stress $(P<0.05)$. There were no significant differences between the two genotypes in the baseline or the evoked corticosterone levels.

set of animals, we examined the performance of the two genotypes with a stronger training protocol that consisted of 3 CS-US pairings with $0.2 \mathrm{~mA}$ shock ( $n=10$ per group). Again, statistical analysis did not show any significant difference in the degree of acquisition between VIP-deficient and WT mice (t-test: CS-US-1: $\mathrm{t}=-0.8, P=0.43$; CS-US-2: $\mathrm{t}=-0.4, P=0.68$; CS-US- $3: \mathrm{t}=1.1, P=0.32$ ). Thus, the loss of VIP does not influence the ability of mice to acquire contextual fear conditioning.

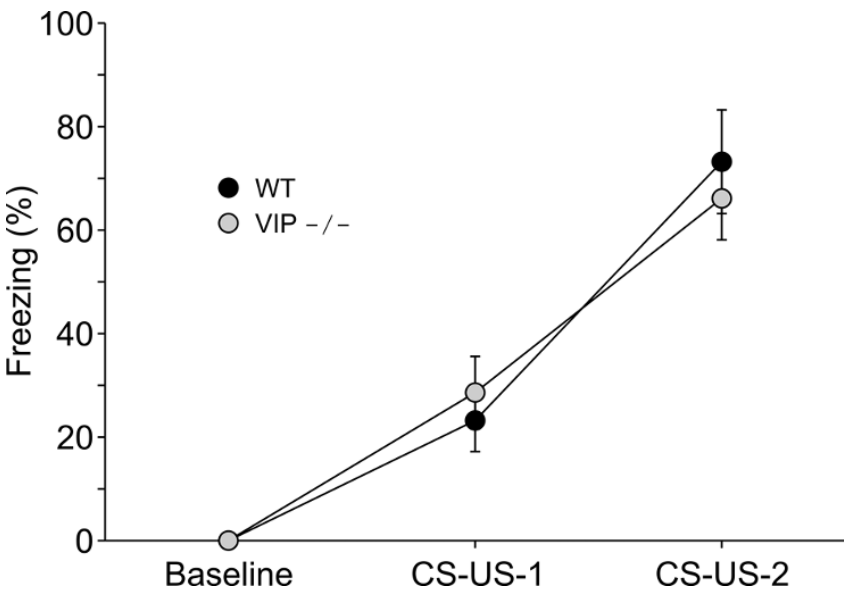

Figure 2

The loss of VIP does not impact acquisition of contextual fear conditioning. WT and VIP-deficient mice were trained in the day (ZT 3). Conditioning consisted of two context (CS) and foot shock (US) pairings. Percent freezing following each context-shock pairing was compared between WT (black circles) and VIP-deficient (grey circles) mice ( $n=8$ per group). There was no difference between the two genotypes in the acquisition of the conditioned fear response.

\section{Contextual recall 24, 48, 72-hrs following training}

Next, we examined if the recall of the contextual fear conditioning is altered in VIP-deficient mice. Groups of VIPdeficient and WT mice ( $n=7-8$ per group) were trained on the weak version of contextual fear conditioning (2CSUS pairings) at ZT 3. Mice were then tested for the recall of fear conditions at either 24-, 48-, or 72-hrs after training (Fig. 3A) with each animal being tested only once. There was no difference in the acquisition of the conditioned fear response, with the group means all between 64 and $70 \%$ freezing. All of the groups (24-, 48-, 72-hr time points) exhibited a robust recall of context as measured by freezing behavior (Fig. 3A). Overall, the VIP-deficient mice exhibited significant reductions in recall compared to WT controls (ANOVA: $\mathrm{F}=9.2, P<0.001$ ). Post-hoc analysis (t-tests) indicated that VIP-deficient mice exhibited significant reductions in recall compared to WT mice when measured at 48- $(\mathrm{t}=2.6, P<0.05)$ and 72 -hrs $(\mathrm{t}=$ $5.4, P<0.001)$ post-training. At 24 -hrs post training, there was no significant difference in contextual recall between the genotypes. To further explore this deficit in longerterm recall, additional groups of WT and mutant mice ( $n$ $=8$ per group) were trained on contextual fear conditioning at ZT 3 and then tested once per day for 7 days (Fig. 3B). Overall, the VIP-deficient mice exhibited significant reductions in recall compared to WT controls (RM ANOVA: $\mathrm{F}=12.6, P<0.01$ ). Post-hoc analysis (t-tests) indicated significant differences between the genotypes when measured at 48- $(\mathrm{t}=2.6, P=0.020), 72-(\mathrm{t}=8.0, P$ $<0.001)$, 96- $(\mathrm{t}=9.3, P<0.001)$ and $120-\mathrm{hrs}(\mathrm{t}=6.2, P<$ 

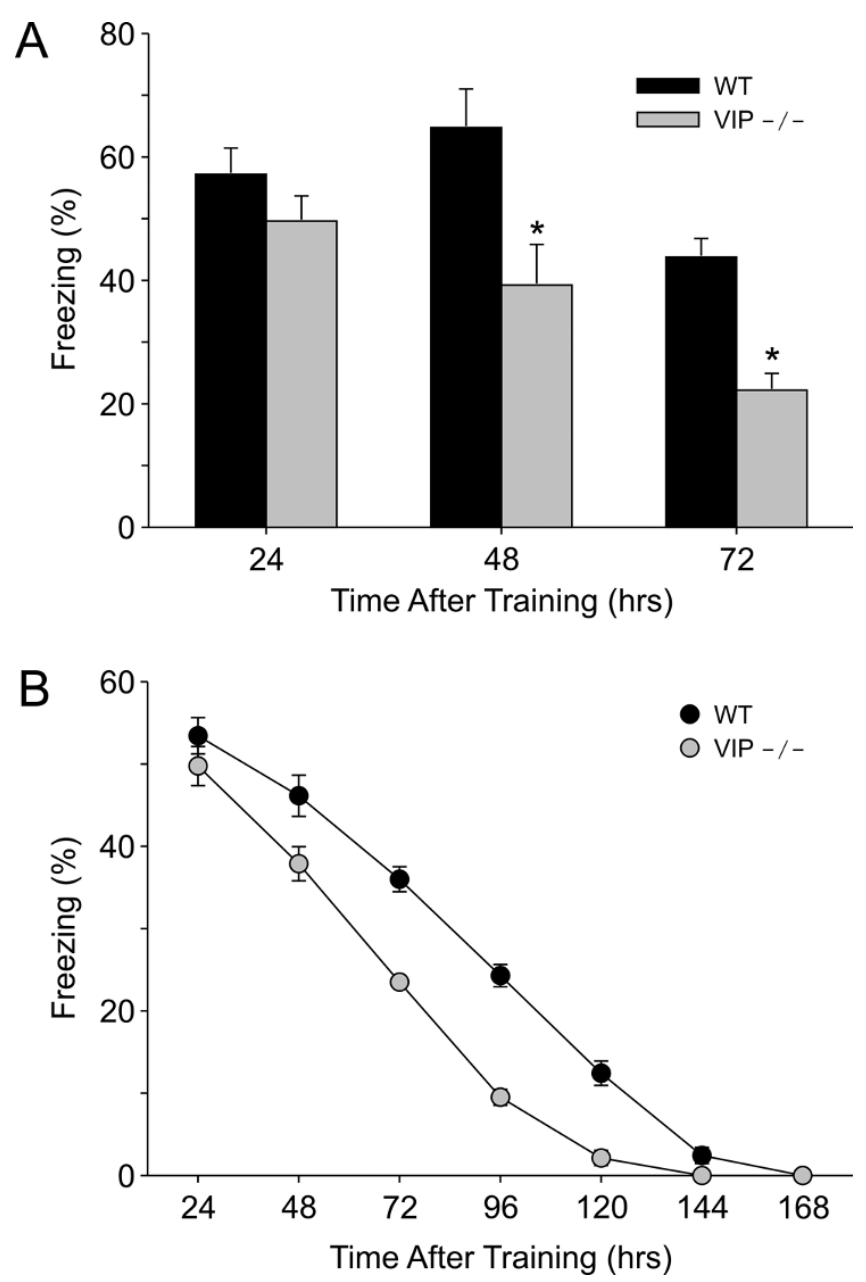

Figure 3

The loss of VIP impaired recall of contextual fear conditioning. A) Groups of VIP-deficient and WT mice ( $n$ =7-8 per group) were trained on the contextual fear conditioning (2 CS-US pairings) at ZT 3. Mice were then tested for the recall of fear conditions one, two, or three days after training with each animal only being tested once. There was no difference the acquisition of the conditioned fear response during training and all of the groups (24-, 48-, 72-hr time points) exhibited a robust recall of context as measured by freezing behavior. VIP-deficient mice (grey bars) exhibited significant reductions in recall compared to WT mice (black bars) when measured at 48- $(P<0.05)$ and 72-hrs $(P<0.00 \mathrm{I})$ post-training. At one day after training, there was no significant difference in the percent freezing between the genotypes. B) In another experiment, VIP-deficient (grey circles) and WT (black circles) mice were trained and then tested for recall once per day for 7 days ( $n=8$ per group). Training and testing were conducted at ZT 3 . The VIP-deficient mice exhibited significant reductions in recall compared to WT controls $(P<0.01)$. Post-hoc analysis (t-tests) indicated significant differences between the genotypes when measured at 48- $(P=0.02), 72-(P<0.00 \mathrm{I}), 96-(P<0.00 \mathrm{I})$ and I20-hrs $(P<0.00 \mathrm{I})$ post-training.
0.001 ) post-training. At 24-hrs post training, there was no significant difference in contextual recall between the WT and VIP-deficient mice. By 144 hrs, the conditioned fear response had extinguished in both groups. Together, this data indicates that the VIP-deficient mice exhibited deficits in the recall of contextual fear conditioning when tested at least 48-hrs after training.

\section{Rhythm in contextual recall under LD conditions}

We previously demonstrated that the recall of contextual recall expresses robust circadian variation [37] and that the circadian system of VIP-deficient mice is compromised [32]. Therefore, we first sought to determine if VIPdeficient mice exhibit a diurnal rhythm in the recall of contextual fear conditioning. Groups of WT and VIP-deficient mice ( $n=8$ per group) were trained at ZT3. The mice were then tested at several intervals after training: 24-, 36, 48-, 60-hrs (Fig. 4). While there was no difference in the acquisition between the genotypes (WT: $66 \pm 5 \%$ freezing; VIP KO: $69 \pm 7 \%$ freezing), the VIP-deficient mice exhibited significant reductions in recall compared to WT mice (RM ANOVA: $\mathrm{F}=12.6, P<0.01$ ). Compared to WT, VIPdeficient mice exhibited significantly less freezing at 36-hr $(\mathrm{t}=2.1, P<0.05), 48-\mathrm{hr}(\mathrm{t}=2.6, P<0.01)$, and $60-\mathrm{hr}(\mathrm{t}=$ $2.5, P<0.01)$ after training. For both genotypes, the recall varied with time (RM-ANOVA: $P<0.001$ ) with post-hoc

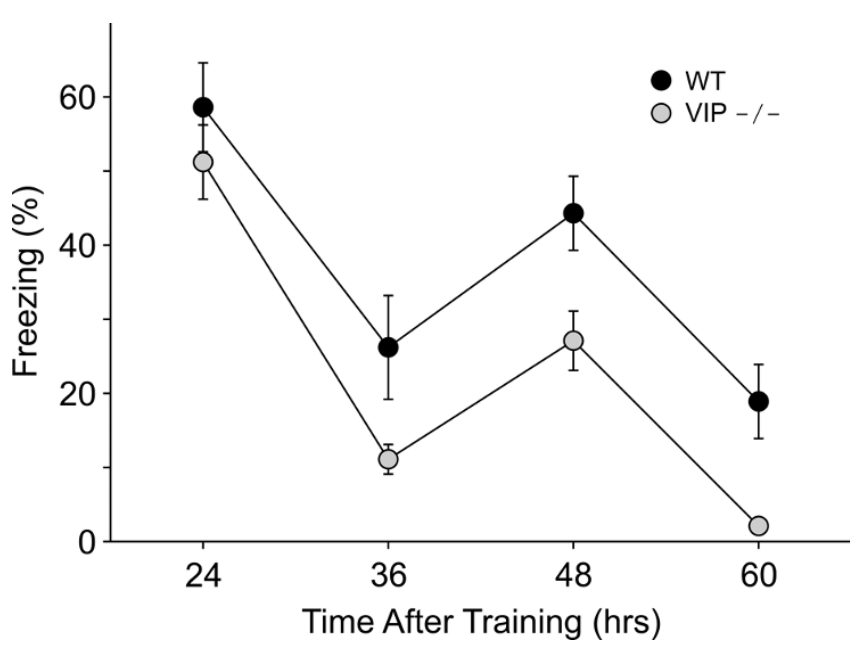

Figure 4

VIP-deficient mice exhibit a daily rhythm in the recall of contextual fear conditioning. Groups of WT (black circles) and VIP-deficient (grey circles) mice were trained at ZT 3 and then tested 24-, 36-, 48- and 60-hrs after training (n $=8$ per group). There was no difference in the acquisition between the genotypes (WT: $66 \pm 5 \%$ freezing; VIP KO: $69 \pm$ $7 \%$ freezing). Both genotypes showed evidence for diurnal rhythmicity in recall with significant $(P<0.05)$ peaks observed at 24- and 48-hrs after training. However, compared to WT mice, the VIP-deficient mice exhibited significantly $(P<0.05)$ lower recall when measured 36-, 48-, or 60hrs after training. 
analysis (Tukey test) indicating that freezing at 24- and 48-hrs after training was significantly $(P<0.05)$ higher than the freezing at 36- and 60-hrs for both strains of mice. Thus, in LD conditions, both WT and VIP-deficient mice exhibited a diurnal rhythm in recall.

\section{Rhythm in contextual recall in behaviorally rhythmic and arrhythmic VIP KO mice}

The next set of experiments was designed to determine whether VIP-deficient mice exhibit circadian rhythms in recall. For these experiments, WT and VIP-deficient mice were held in constant conditions in cages with running wheels. WT mice all exhibited clear circadian rhythms in wheel-running activity. While all of the VIP-deficient mice exhibited disrupted rhythms [32], some of the mutant mice are arrhythmic while others continue to express circadian rhythms in locomotor activity (Fig. 5A,B). For these experiments, groups of rhythmic and arrhythmic VIP-deficient mice ( $n=8$ per group) were trained at CT3. For the rhythmic VIP-deficient mice, CT3 (subjective day) was estimated based on wheel running activity. For the arrhythmic VIP-deficient mice, CT 3 was estimated based on the activity projected from the prior LD cycle. Due to the lack of regular activity onset in these mice, a $6 \mathrm{hr}$ phase advance was assumed and tau was also assumed to be around $22 \mathrm{hr}$ based on the activity patterns of the rhythmic VIP-/- mice. Both groups of mice were trained in constant darkness at CT3 using a stronger training protocol consisting of 3 CS-US pairings. There was no difference in the acquisition of conditioning between the 2 groups (Rhythmic: $94 \pm 4 \%$; Arrhythmic: $91 \pm 5 \%$ ). The mice were then tested for recall 24-hrs after training and every 6-hrs subsequently for a total of 2 days (Fig. 5C). For both rhythmic and arrhythmic groups, the recall varied with time (RM ANOVA: $P<0.001$ ) with post-hoc analysis (Tukey test) indicating that freezing at 24-, 48- and 72-hrs after training was significantly $(P<0.05)$ higher than the freezing at the other intervals. Thus, VIP-deficient mice that exhibited arrhythmic wheel-running activity still express circadian rhythms in the recall of contextual fear conditioning.

\section{Period2 message is rhythmically expressed in the hippocampus of VIP-deficient mice}

The genes responsible for the generation of circadian oscillations are expressed in brain regions outside of the suprachiasmatic nucleus, including the hippocampus $[38,39]$. This rhythm in gene expression in the hippocampus may be critical for the rhythms in recall that we and others have observed under various contextual memory tasks. In order to determine if the message coding for Period2 is rhythmic in the hippocampus of VIP-deficient mice, we used in situ hybridization (ISH) to measure Period2 message in the hippocampus of mice at subjective day and night (CT 10 and 23; Fig. 6A). Expression of
Period 2 mRNA was observed throughout the rostrocaudal extent of the hippocampus and was largely restricted to the pyramidal cell layers and the Dentate Gyrus. In the hippocampus of the VIP-deficient mice, the mean optical density (OD) of Period2 labeling was significantly higher at subjective day than in the subjective night (Fig. 6B; $\mathrm{t}-$ test: $\mathrm{t}=-2.5, P=0.03$ ). The Period2 expression did not significantly vary between VIP-deficient and WT mice. Among the hippocampal subregions, the CA3 pyramidal cell layers showed the most robust circadian variation in labeling (CA3 CT 10: $1.3 \pm 0.2 \mathrm{OD}, n=9$; CA3 CT 23: 2.2 \pm 0.2 OD, $n=6$; t-test: $\mathrm{t}=-2.92, P<0.01)$. The Period2 sense probe did not exhibit labeling in the brain under identical hybridization conditions (data not shown). These data demonstrate at least one clock gene is rhythmically expressed in the hippocampus of VIP-deficient mice and raise the possibility that extra-SCN circadian oscillators may drive the rhythms in recall in these mice.

\section{Discussion}

The neuropeptide VIP and its receptors are expressed in regions of the brain implicated in the control of learned behaviors including the hippocampus, cortex, amygdala and hypothalamus [e.g. [4-6]]. In these regions, VIP is most commonly expressed in GABAergic interneurons [e.g. [40-43]] that may use this peptide to communicate with specific post-synaptic targets. However, it is equally plausible that VIP functions more as a paracrine signal acting at sites more distant than just the adjacent postsynaptic neurons. While the physiological actions of this neuropeptide have not been extensively studied, VIP regulates synaptic transmission [e.g. [7,8]] and intrinsic membrane currents [e.g. [9-12]]. Thus, this neuropeptide can be a potent modulator of neural activity and function in specific circuits in the adult nervous system. Given this anatomical distribution and potential physiological functions in both the developing and mature nervous system, the loss of VIP may well have been expected to have global influences on learning and memory. However, the present study found that the deficits in the VIP-deficient mice were quite selective. Deficits were not observed in foot shock-evoked fear behavior. This demonstrates that the basic sensory and motor processes controlling this behavior are intact in the VIP-deficient mice. Similarly, the shock-evoked corticosterone response was intact in these mutant mice. Given that VIP is expressed in the adrenals and the circadian system that regulate corticosterone secretion, we felt that it was important to confirm that this aspect of the stress response was functioning in the VIPdeficient mice. Finally, we observed no deficits in the VIPdeficient mice in the acquisition of fear conditioning or in the recall measured at 24-hrs after training. Clearly, the circuitry involved in the acquisition of contextual fear conditioning is either not regulated by VIP or there is 

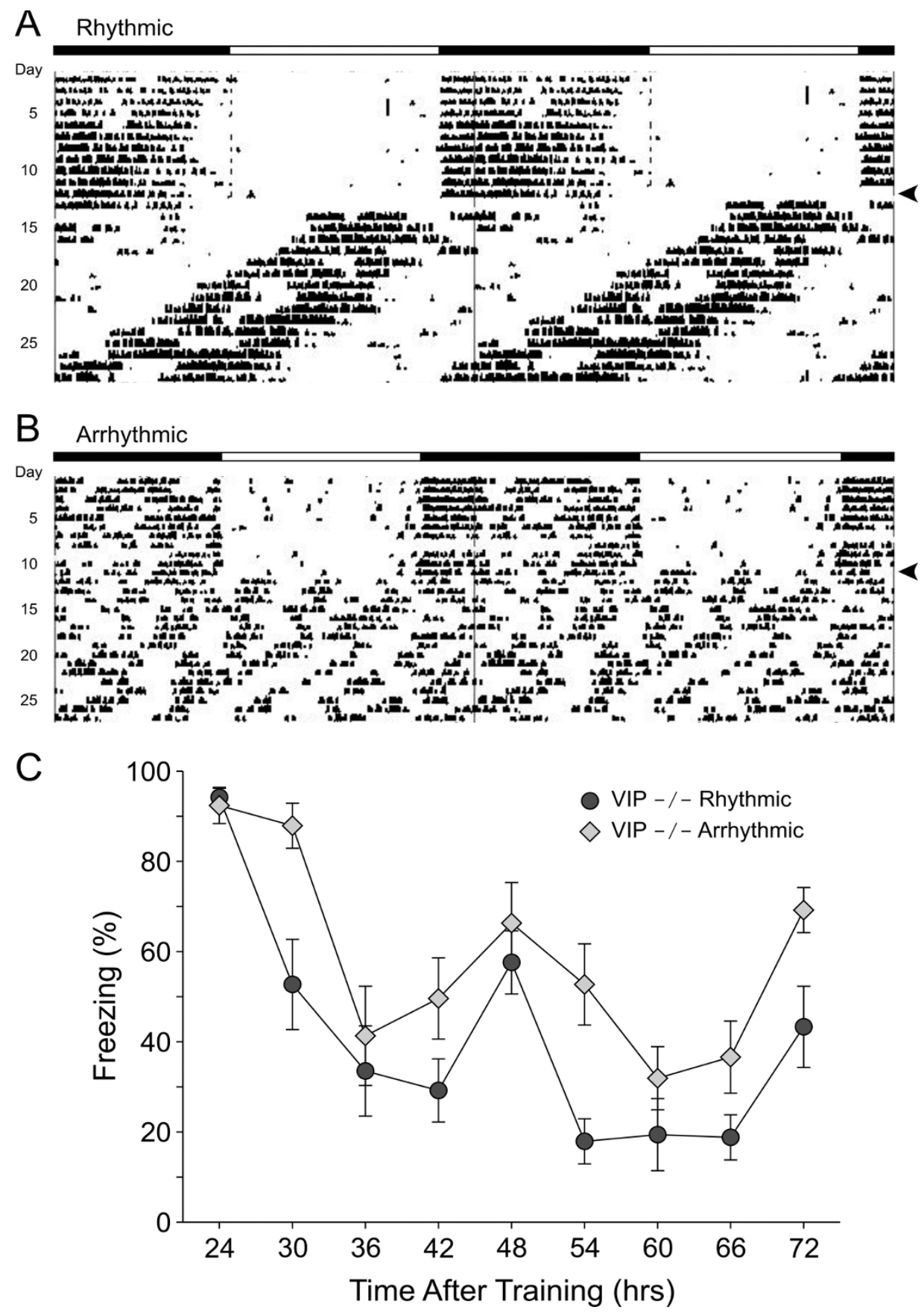

Figure 5

VIP-deficient mice that have arrhythmic patterns of wheel-running activity exhibit a circadian rhythm in the recall of contextual fear conditioning. A) Example of wheel-running activity from a VIP-deficient mouse that maintained a circadian rhythm in wheel-running activity. Bars at top of panel indicate the LD cycle. The locomotor activity is double-plotted as an aid to visual analysis. The mouse was placed into DD on the day indicted by the arrow on the right. B) Example of wheelrunning activity from a VIP-deficient mouse that was judged to by arrhythmic on a circadian time-scale by visual analysis and periodogram. C) Both rhythmic and arrhythmic VIP-deficient mice were trained at CT 3 and then tested every 6-hrs between 24- and 72-hrs after training. These experiments were conducted in constant darkness to measure the endogenous rhythmicity. For the rhythmic mice (dark grey circles), the onset of locomotor activity was used to estimate phase while, for the arrhythmic mice (grey diamonds), the time of the prior LD cycle was used. Both groups of VIP-deficient mice exhibited circadian rhythms in the recall of fear conditioning with significant $(P<0.05)$ peaks $24-, 48-$, and 72 -hrs post training. 

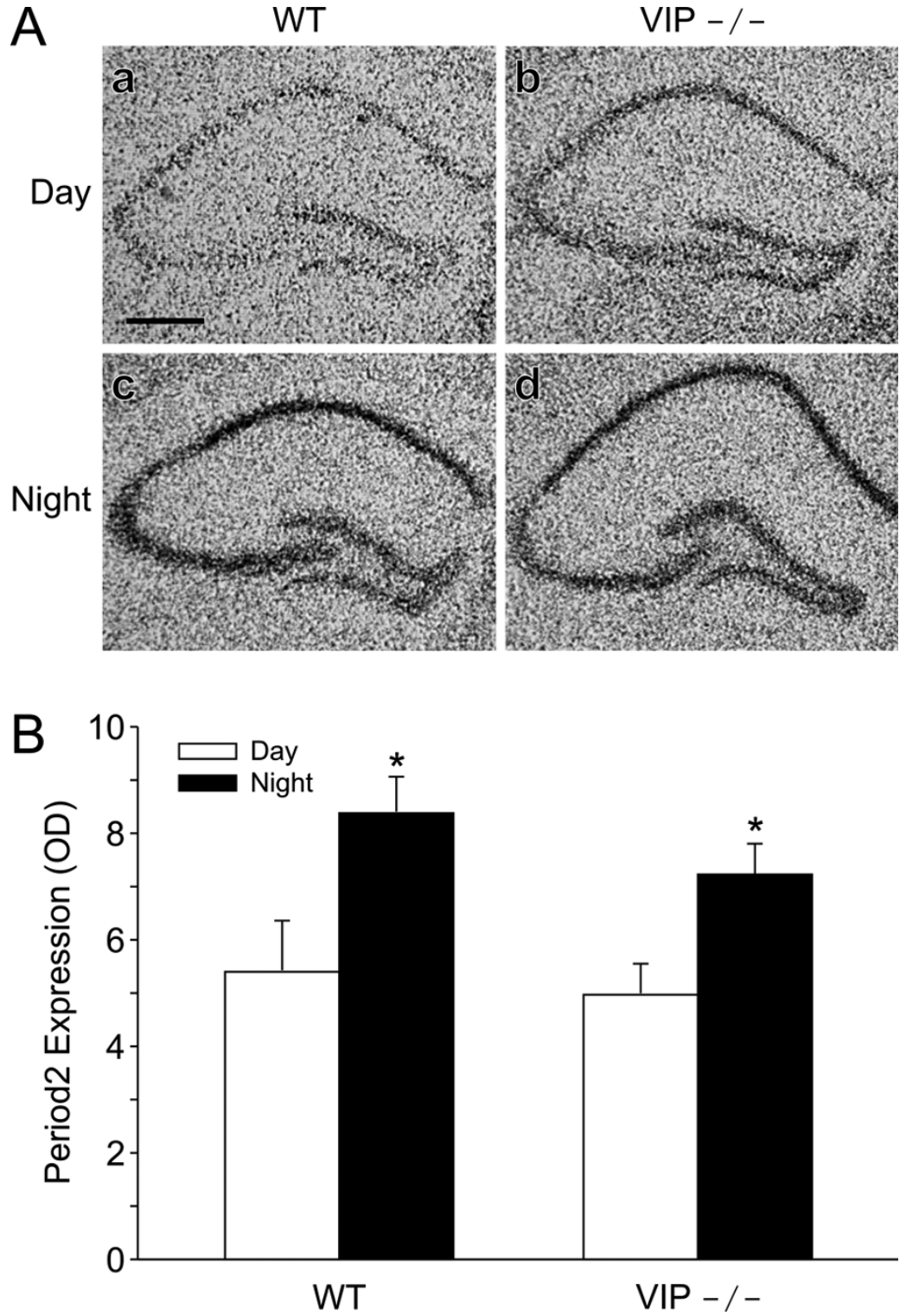

Figure 6

A circadian rhythm in Period2 mRNA in the hippocampus of VIP-deficient mice as measured by ISH. A) Film images of ISH for Period2 on tissue sections taken from WT and VIP-deficient mice sacrificed during the subjective day (CTI0; a, b) and subjective night (CT 23; c, d). The scale bar equals $0.5 \mathrm{~mm}$. B) Optical density measurements of Period2 labeling in the hippocampus of WT and VIP-deficient mice during the subjective day (CT 10, white bars) and subjective night (CT 23, black bars). The Period2 hybridization signal was significantly $(P<0.05)$ higher in the subjective night in the hippocampus of both lines of mice.

compensation for the loss of this neuropeptide in these transgenic mice.

The recall of the contextual fear conditioning was affected by the loss of VIP. These recall deficits were seen in three independent experiments including those mice only tested for recall a single time (Fig. 3A), those tested daily (Fig. 3B), and those tested every 12-hrs (Fig. 4). These results fit with previous pharmacological studies that have raised the possibility that VIP plays a physiological role in the modulation of learning and memory. For example, administration of VIP into rat hippocampus following training on a passive avoidance task induced recall in rats tested 24-hrs later, while administration of a VIP antagonist enhanced retention [14]. Other studies have also found evidence that the central administration of VIP 
impairs recall in passive avoidance learning [13,17]. Spatial learning as measured by the water maze was also impaired by the ventricular administration of this neuropeptide $[15,16]$. In contrast, one study reported that the intracerebral administration of a VIP receptor antagonist, but not VIP itself, inhibited performance on the Morris water maze [18]. In addition, learning deficits in mice carrying a chimeric VIP-diptheria toxin gene have been reported [19]. These transgenic mice lost about $20 \%$ of VIP content as measured by radioimmunoassay and exhibited learning deficits as measured by the Morris water maze. Taken together, these studies suggest that abnormally high or low levels of VIP can interfere with the acquisition and recall of specific learned behaviors.

The VIP-deficient mice used in the present study are a traditional transgenic model in which the gene coding for VIP has been inactive throughout development. VIP is expressed early in the fetal brain [44] with VIP binding sites abundant on the floor plate of the neural tube [45]. While not extensively studied in central neurons, VIP is a neurotrophic factor that can regulate neural growth, migration, and process formation [reviewed by [46-48]] and, through these developmental mechanisms, influence the neural circuits involved in learning and memory functions. A recent study examined the consequences of pharmacologically blocking VPAC receptors during embryogenesis and examining potential cognitive deficits in the adult offspring [30]. Male, but not female, treated mice exhibited deficits in contextual fear conditioning and social behavior. The selective set of behavioral deficits coupled with the gender difference led these authors to propose these mice as a model for the behavioral deficits of autism. Like the VIP-deficient mice, these mice treated developmentally with the VPAC antagonist did not show deficits in acquisition or in recall measured 24-hrs after training. The male offspring did show recall deficits when measured 48 -hrs after training. Thus, the memory deficits observed in the transgenic animals in the present study could well be due to a loss of VIP early in development.

As described before, there is strong evidence that VIP and the $\mathrm{VPAC}_{2} \mathrm{R}$ are critical for the normal functioning of the circadian system [reviewed by [49]]. Together, these data indicate that VIP and $\mathrm{VPAC}_{2} \mathrm{R}$ are critical for the generation of behavioral rhythms in mice and that the deficit occurs at the level of the SCN. Furthermore, the VPAC ${ }_{2} \mathrm{R}$ deficient mice even lose the daily rhythms in clock gene expression that are thought to lie at the heart of the machinery for the generation of daily rhythms $[33,50]$. Given the overwhelming data that the loss of VIP influences the generation of circadian oscillations, the finding that these mutants showed no apparent deficiency in the diurnal and circadian regulation in recall was unexpected. This disassociation was particularly striking in the case of
VIP-deficient mice that exhibited arrhythmic locomotor activity. The $6 \mathrm{hr}$ interval in testing may have occluded small changes in peak recall time, which most likely tracks with the intrinsic free-running period of the animals. However, the frequency of testing was sufficient to show that there remains an optimal time of day, which tracks with the same time of day as the initial training exercise, even in mice with arrhythmic wheel-running activity. This is consistent with the phenomenon of "time-stamping" of learned behavior as observed in hamsters $[51,52]$ and by us in mice [37]. What's more, this time-stamp phenomenon may be independent of the SCN. Lesioning the SCN of rats does not affect the time-stamped training of a Tmaze reward task [53]. Previous work has found that these behaviorally arrhythmic VIP-deficient mice also exhibit arrhythmic electrical activity rhythms when measured at the level of the SCN [35]. We now show that these arrhythmic mice exhibited clear rhythms in recall and these rhythms were extremely similar to those exhibited by the behaviorally rhythmic mice. Thus, the loss of circadian function in these arrhythmic VIP-deficient mice had no obvious impact on the rhythms in recall suggesting that a rhythmic SCN may not be necessary for the circadian rhythm in recall. In recent years, it has become clear that many of the "clock genes" are expressed outside of the SCN [e.g. [54,55]]. This raises the possibility that oscillators outside of the SCN may drive the rhythms in recall of learned behaviors. While we did not directly address this possibility in the present study, we did examine the expression of one clock gene, Period2, in the hippocampus. We found that levels of this gene continue to show circadian differences in the hippocampus of VIP-deficient mice (Fig. 6). This type of rhythmic expression is at least consistent with the possibility that extra-SCN rhythms in gene expression may be directly tied to the rhythms in recall observed in fear-conditioned mice.

In mammals, neurons in the hippocampus [[38,39], present data], olfactory bulb [56], SCN [e.g. [55]], and other brain regions [54] have now been shown to generate oscillations in circadian gene expression. This pool of data contributes to the view that the circadian system is comprised of multiple oscillatory components, with the role of the SCN being a master timer synchronizing these disparate cell populations [e.g. [57]]. With this new view of clock genes and circadian organization, it becomes critical to determine the tissue-specific function of these genes. Logically, local rhythms in clock gene expression could serve to control the temporal program of gene expression and physiology specific to the hippocampus, as recently demonstrated in liver [58]. However, unfortunately, we still do not know much about the functional significance of clock gene expression outside of the SCN. The VIP-deficient mice with weakened rhythms in SCN electrical activity may represent an advantageous model to explore 
coupling between different circadian oscillators. Our data with contextual fear conditioning raise the possibility that these rhythms in recall or memory are only weakly coupled to core time-keeping mechanisms in the SCN.

\section{Conclusion}

We found that VIP-deficient mice exhibited normal shock-evoked freezing behavior and increases in corticosterone. Similarly, these mutant mice exhibited no deficits in the acquisition or recall of the fear-conditioned behavior when tested 24-hours after training. The VIP-deficient mice exhibited a significant reduction in recall when tested 48-hours or longer after training. Surprisingly, we found that the VIP-deficient mice continued to express circadian rhythms in the recall of the training even in those individual mice whose wheel running wheel activity was arrhythmic. One mechanistic explanation is suggested by the finding that daily rhythms in the expression of the clock gene Period2 continue in the hippocampus of VIPdeficient mice. Together these data suggest that the neuropeptide VIP regulates the recall of at least one learned behavior but does not impact the circadian regulation of this behavior.

\section{Methods}

\section{Experimental animals}

We obtained two-month old male mice lacking the gene encoding for the neuropeptides VIP and PHI that had been backcrossed to the C57BL/6J strain for 12 generations [32]. Wild type (WT) littermates were used when available, but age-matched controls were obtained when necessary. All mice were housed in cages within light-tight chambers with controlled lighting conditions. The experimental protocols used in this study were approved by the UCLA Animal Research Committee and all recommendations for animal use and welfare, as dictated by the UCLA Division of Laboratory Animals and the guidelines from the National Institutes of Health, were followed.

\section{Training and testing procedure}

Contextual fear conditioning was performed using previously published protocols [37]. Mice were entrained to a 12:12 light-dark cycle (LD) for at least one week prior to the start of all experiments (light intensity $36 \mu \mathrm{W} / \mathrm{cm}^{2} \cong$ 120 lux). Zeitgeber Time 0 (ZT0) corresponds to the start of the light period with experiments typically done at ZT3 (early day). Mice were individually handled for approximately $1 \mathrm{~min}$ a day, a week prior to the start of the experiment to reduce the arousal associated with handling. Each day, animals were handled at different times of the day or night to ensure that they did not entrain to handling by the experimenter at a specific time. Animals were handled by taking individuals out of their home cages and placing them on the experimenter's arm. Following entrainment, the animals were trained in separate contex- tual conditioning cages $(28 \times 21 \times 22 \mathrm{~cm}$ : Lafayette Instruments). The chambers were constructed from aluminum (sidewalls) and Plexiglas (rear wall, ceiling, and hinged front door). A total of 4 identical conditioning cages were used that allowed 4 mice to be trained and tested per session. The floor of each cage consisted of 33 stainless steel rods ( $4 \mathrm{~mm}$ diameter, $4 \mathrm{~mm}$ apart) connected to a shock scrambler and generator (Master Shock, Lafayette Instruments). To remove any variability in olfactory learning, the inside of each cage was wiped with $0.01 \%$ benzaldehyde before the start of each experiment. On the day of training, mice were placed individually into cages and allowed to acclimatize to the new environment (conditioned stimulus, CS) for 3 min after which time animals received a 2 sec footshock (unconditioned stimulus, US).

Depending on whether the animals were trained on a strong or weak training task, the number of CS-US pairing and US intensity was varied. The training protocol normally consisted of 2 CS-US pairings with a $0.2 \mathrm{~mA}$ US. In some cases, a stronger training protocol consisting of 3 CS-US pairings with a $0.2 \mathrm{~mA}$ US was used. The inter-trial interval was 64 seconds in all protocols. At the end of the last context-shock pairing the mice were left in the cage for a further $64 \mathrm{sec}$, after which they were returned to the home cages. Animals were placed individually into the same conditioning chamber and left there for $8 \mathrm{~min}$. The behavior of the mice, whether it was freezing or mobile was noted. The training procedures were automatically controlled by a computer using the ABET behavioral software (ABET systems, Lafayette Instruments). Control experiments were also carried out where animals were placed in context cages at times points corresponding to those in experiments of animals tested every 6 or $12 \mathrm{hrs}$. This 'baseline' freezing level was subtracted from freezing in animals following training and subsequent repeated testing.

Freezing was defined as the complete absence of somatic and motility movements with the exception of respiratory movements. For acquisition and context recall, an $8 \mathrm{sec}$ time sampling procedure was used in which each animal was observed 8 times per min interval (in this case a minute refers to a 64 sec block) and these were averaged to yield an estimate of percentage time freezing. During training, freezing was measured $64 \mathrm{sec}$ before the first CSUS pairing (baseline) and during the $64 \mathrm{sec}$ inter-trial interval immediately after each CS-US pairing, giving 8 observations per mice for baseline and for each subsequent CS-US pairing respectively. For context testing, each animal was observed a total of 64 times. To determine the degree of learning during training, percent freezing was calculated as the number of times each animal was observed to be immobile over 8 observations. For context testing, percent freezing was calculated as the number of 
times each animal was observed to be immobile over 64 observations

\section{Wheel-running behavior analysis}

The mice were housed individually and their wheel-running activity was recorded as revolutions per 3 min interval as previously described [32]. The running wheels and data acquisition system were obtained from Mini Mitter Co. (Bend, OR). The mice were first exposed to a 12:12 LD cycle for $2-3$ weeks (light intensity $36 \mu \mathrm{W} / \mathrm{cm}^{2} \cong 120$ lux). The mice were then placed into constant darkness (DD) to assess their free-running activity pattern. Circadian time (CT) was determined by activity records with activity onset denoted as CT12. Training in DD was performed after 2-4 days in constant darkness. In the dark portion of LD conditions, as well as under DD conditions, handling of mice was carried out with the aid of an infrared viewer (FJW Industries, Ohio). Behavior during acquisition and recall was recorded with the aid of a video camera that had an in-built infrared system, which enabled us to record the animals in both light and dark conditions.

\section{Corticosterone measurements}

Circulating corticosterone concentrations were determined 20 min after initiation of the weak training protocol. Trunk blood was collected by decapitation after isoflurane treatment. To obtain serum, blood samples were allowed to clot at room temperature for $30 \mathrm{~min}$ prior to centrifugation at $1000 \times g$. The supernatant was stored at $-20^{\circ} \mathrm{C}$ until assayed. Samples were typically diluted 100 -fold prior to assay. Serum corticosterone concentration was measured by competitive enzyme immunoassay (Correlate-EIA Corticosterone kit, Assay Designs, Michigan). The intra-assay $\mathrm{CV}$ was $<8 \%$, the inter-assay $\mathrm{CV}$ was $<13.1 \%$ and the sensitivity was $27 \mathrm{pg} / \mathrm{ml}$.

\section{In Situ Hybridization}

A plasmid (pCRII, Invitrogen) containing the cDNA for mPer2 (9-489 nt, accession number AF035830) was generously provided by Dr. D. Weaver (Univ. Mass.) and insert identity was confirmed by sequencing using the M13R primer. To generate antisense and sense templates for ISH, plasmids were linearized overnight, phenol:chloroform extracted, ethanol precipitated and resuspended in DEPC-treated water. Riboprobes were synthesized from 1 $\mu \mathrm{g}$ of template cDNA in a reaction mixture containing 100 microCi of UTP ${ }^{35} \mathrm{~S}(1,250 \mathrm{Ci} / \mathrm{mmol}$, Perkin Elmer, Wellesley, MA), $5 \times$ transcription buffer (Promega, Madison, WI), 0.1 M DTT (Promega, Madison, WI), $10 \mathrm{mM}$ of each rATP, rCTP, rGTP, $40 \mathrm{U}$ RNase Inhibitor, and the appropriate RNA transcriptase (SP6, or T7) for $3 \mathrm{hrs}$ at $37^{\circ} \mathrm{C}$. The in vitro transcription reaction was DNase I treated, then unincorporated nucleotides were removed using the RNase-free microfuge spin columns (Bio-Spin 30, Biorad, Hercules, CA) and probe yields were calculated by scintil- lation counting. ISH on tissue sections was done using previously described procedures (Lambert et al., 2005). Briefly, tissue sections were fixed in $4 \%$ paraformaldehyde, air-dried and blocked by acetylation with acetic anhydride, followed by a series of dehydration steps. After air drying, slides were placed in prehybridization buffer (50\% formamide, $3 \mathrm{M} \mathrm{NaCl}, 20 \mathrm{mM}$ EDTA, $400 \mathrm{mM}$ Tris, pH 7.8, 0.4\% SDS, $2 \times$ Denhardt's, $500 \mathrm{mg} / \mathrm{mL}$ tRNA, and $50 \mathrm{mg} / \mathrm{mL}$ polyA RNA) for $1 \mathrm{hr}$ at $55^{\circ} \mathrm{C}$. Sections were hybridized overnight at $55^{\circ} \mathrm{C}$ in humidified chambers in hybridization buffer ( $50 \%$ formamide, $10 \%$ dextran sulfate, $3 \mathrm{M} \mathrm{NaCl}, 20 \mathrm{mM}$ EDTA, $400 \mathrm{mM}$ Tris, pH 7.8, 0.4\% SDS, $2 \times$ Denhardt's, $500 \mathrm{mg} / \mathrm{mL}$ tRNA, and $50 \mathrm{mg} / \mathrm{mL}$ polyA RNA, $40 \mathrm{mM}$ DTT), where each slide was incubated with 1-4 million cpm/70 $\mathrm{mL}$ of a riboprobe. All posthybridization washes contain $1 \mathrm{mM}$ sodium thiosulfate, except in the RNase A and ethanol washes. Following hybridization, the slides were washed for $15 \mathrm{~min}$ in $4 \times$ SSC, at their respective hybridization temperatures, in $2 \times$ SSC for $1 \mathrm{hr}$ at room temperature, then RNase A (20 micrograms $/ \mathrm{mL}$ ) treated at $37^{\circ} \mathrm{C}$ for $30 \mathrm{~min}$ to remove unbound probe. To further reduce non-specific hybridization, the slides were washed twice in $2 \times \mathrm{SSC}$ at $37^{\circ} \mathrm{C}$, and for $1 \mathrm{hr}$ in $0.1 \times \mathrm{SSC}$ at $62-67^{\circ} \mathrm{C}$. Slides were serially dehydrated in ethanol containing $0.3 \mathrm{M}$ ammonium acetate and exposed to Kodak Biomax MR film (Kodak, Rochester, NY) along with a ${ }^{14} \mathrm{C}$ slide standard (American Radiolabeled Chemicals, St. Louis, MO). The slides were counterstained with $0.04 \%$ thionin dye to serve as a reference. Densitometric analysis of hybridization intensity was done as described using NIH image software [59].

\section{Statistical Analysis}

To make simple comparisons between groups, t-tests were used. To compare recall for animals tested once at 24-, 48or 72-hrs following training, one-way analysis of variance (ANOVA) was used followed by t-tests for pair-wise comparisons. In the cases in which repeated measurements were made from single animals, the data was analyzed using a one-way repeated measure (RM) ANOVA followed by Tukey's test for multiple comparisons. For all tests, values were considered significantly different at $P<0.05$.

\section{Abbreviations}

CS: conditioned stimulus; CT: circadian time; ISH: in situ hybridization; LD: light-dark; OD: optical density; SCN: suprachiasmatic nuclei; US: unconditioned stimulus; VIP: vasoactive intestinal peptide; WT: wild type; ZT: zeitgeber time.

\section{Authors' contributions}

$\mathrm{DC}$ and $\mathrm{AH}$ carried out the fear conditioning experiments; DHL performed the corticosterone measurements and helped with the manuscript preparation; JMD carried out the ISH; CSC drafted the manuscript. All authors partici- 
pated in the experimental design and approved the final manuscript.

\section{Acknowledgements}

Supported by NIH \#HL84240 to CSC and NIH T32 NS-07I0I-27 to JMD. The VIP-deficient mice were generously donated by Dr. James Waschek, University of California, Los Angeles. We would like to thank Dr. L. Wang for comments on a draft of the manuscript.

\section{References}

I. Ishihara T, Shigemoto R, Mori K, Takahashi K, Nagata S: Functional expression and tissue distribution of a novel receptor for vasoactive intestinal polypeptide. Neuron 1992, 8:8I I-8I9.

2. Lutz EM, Sheward WJ, West KM, Morrow JA, Fink G, Harmar AJ: The VIP2 receptor: molecular characterisation of a cDNA encoding a novel receptor for vasoactive intestinal peptide. FEBS Lett 1993, 334:3-8.

3. Usdin TB, Bonner TI, Mezey E: Two receptors for vasoactive intestinal polypeptide with similar specificity and complementary distributions. Endocrinology 1994, 135:2662-2680.

4. Dietl MM, Hof PR, Martin JL, Magistretti PJ, Palacios JM: Autoradiographic analysis of the distribution of vasoactive intestinal peptide binding sites in the vertebrate central nervous system: a phylogenetic study. Brain Res 1990, 520:14-26.

5. Sheward W], Lutz EM, Harmar A): The distribution of vasoactive intestinal peptide2 receptor messenger RNA in the rat brain and pituitary gland as assessed by in situ hybridization. Neuroscience 1995, 67:409-4I8.

6. Vertongen P, Schiffmann SN, Gourlet P, Robberecht P: Autoradiographic visualization of the receptor subclasses for vasoactive intestinal polypeptide (VIP) in rat brain. Peptides 1997 , I 8: 1547-1554

7. Ciranna L, Cavallaro S: Opposing effects by pituitary adenylate cyclase-activating polypeptide and vasoactive intestinal peptide on hippocampal synaptic transmission. Exp Neurol 2003, 184:778-784.

8. Itri J, Colwell CS: Regulation of inhibitory synaptic transmission by vasoactive intestinal peptide (VIP) in the mouse suprachiasmatic nucleus. I Neurophysiol 2003, 90: I589-I597.

9. Haug T, Storm JF: Protein kinase A mediates the modulation of the slow $\mathrm{Ca}(2+)$-dependent $\mathrm{K}(+)$ current, I(sAHP), by the neuropeptides CRF, VIP, and CGRP in hippocampal pyramidal neurons. J Neurophysiol 2000, 83:207I-2079.

10. Pakhotin P, Harmar AJ, Verkhratsky A, Piggins H: VIP receptors control excitability of suprachiasmatic nuclei neurones. Pflugers Arch 2006, 452:7-15.

II. Sun QQ, Prince DA, Huguenard JR: Vasoactive intestinal polypeptide and pituitary adenylate cyclase-activating polypeptide activate hyperpolarization-activated cationic current and depolarize thalamocortical neurons in vitro. Neurosci 2003, 23:275।-2758.

12. Wang YY, Aghajanian GK: Excitation of locus coeruleus neurons by vasoactive intestinal peptide: role of a CAMP and protein kinase A. J Neurosci 1990, 10:3335-3343.

13. Cottrell GA, Veldhuis HD, Rostene WH, de Kloet ER: Behavioral actions of vasoactive intestinal peptide (VIP). Neuropeptides 1984, 4:33|-34|.

14. Flood JF, Garland JS, Morley JE: Vasoactive intestinal peptide (VIP): an amnestic neuropeptide. Peptides 1990, I I:933-938.

15. Itoh S, Takashima A, Morimoto T: Impaired spatial learning by vasoactive intestinal peptide in Morris water maze task in the rat. Can J Physiol Pharmacol 1994, 72:25-29.

16. Takashima A, Maeda Y, Itoh S: Influence of chronic intracerebroventricular infusion of vasoactive intestinal peptide (VIP) on memory processes in Morris water pool test in the rat. Peptides 1993, 14:1073-1078.

17. Takashima A, Maeda Y, Itoh S: Vasoactive intestinal peptide (VIP) causes memory impairment in passive avoidance responding of the rat. Peptides 1993, 14:1067-107|

18. Glowa JR, Panlilio LV, Brenneman DE, Gozes I, Fridkin M, Hill JM: Learning impairment following intracerebral administration of the HIV envelope protein gp I 20 or a VIP antagonist. Brain Res 1992, 570:49-53.
19. Gozes I, Glowa J, Brenneman DE, McCune SK, Lee E, Westphal H: Learning and sexual deficiencies in transgenic mice carrying a chimeric vasoactive intestinal peptide gene. I Mol Neurosci 1993, 4:185-193.

20. Gozes I, Bardea A, Reshef A, Zamostiano R, Zhukovsky S, Rubinraut $S$, Fridkin M, Brenneman DE: Neuroprotective strategy for Alzheimer disease: intranasal administration of a fatty neuropeptide. Proc Natl Acad Sci USA 1996, 93(1):427-432.

21. Gozes I, Perl O, Giladi E, Davidson A, Ashur-Fabian O, Rubinraut S, Fridkin M: Mapping the active site in vasoactive intestinal peptide to a core of four amino acids: neuroprotective drug design. Proc Natl Acad Sci USA 1999, 96(7):4|43-4I48.

22. Brenneman DE, Nicol T, Warren D, Bowers LM: Vasoactive intestinal peptide: a neurotrophic releasing agent and an astroglial mitogen. J Neurosci Res 1990, 25:386-394.

23. Pellegri G, Magistretti PJ, Martin JL: VIP and PACAP potentiate the action of glutamate on BDNF expression in mouse cortical neurones. Eur J Neurosci 1998, 10:272-280.

24. Brenneman DE, Phillips TM, Hauser J, Hill JM, Spong CY, Gozes I: Complex array of cytokines released by vasoactive intestinal peptide. Neuropeptides 2003, 37(2): I I I-I I9.

25. Gozes I: Activity-dependent neuroprotective protein: from gene to drug candidate. Pharmacol Ther 2007, I I 4(2): | 46-I54.

26. Gozes I, Brenneman DE: A new concept in the pharmacology of neuroprotection. J Mol Neurosci 2000, I 4(I-2):6I-68.

27. Harmar AJ: Family-B G-protein-coupled receptors. Genome Biol 200I, 2:REVIEWS30I3.

28. Abel T, Nguyen PV, Barad M, Deuel TA, Kandel ER, Bourtchouladze $R$ : Genetic demonstration of a role for PKA in the late phase of LTP and in hippocampus-based long-term memory. Cell 1997, 88:615-626.

29. Pineda VV, Athos JI, Wang H, Celver J, Ippolito D, Boulay G, Birnbaumer L, Storm DR: Removal of $\mathbf{G}$ (ialphal) constraints on adenylyl cyclase in the hippocampus enhances LTP and impairs memory formation. Neuron 2004, 4I: I53-163.

30. Hill JM, Cuasay K, Abebe DT: Vasoactive intestinal peptide antagonist treatment during mouse embryogenesis impairs social behavior and cognitive function of adult male offspring. Exp Neurol 2007, 206: I0I-II3.

3I. Gozes I, Lilling G, Glazer R, Ticher A, Ashkenazi IE, Davidson A Rubinraut $S$, Fridkin M, Brenneman DE: Superactive lipophilic peptides discriminate multiple vasoactive intestinal peptide receptors. J Pharmacol Exp Ther 1995, 273(1):16I-167.

32. Colwell CS, Michel S, Itri J, Rodriguez W, Tam J, Lelievre V, Hu Z, Liu $X$, Waschek JA: Disrupted circadian rhythms in VIP- and PHIdeficient mice. Am J Physiol Regul Integr Comp Physiol 2003, 285:R939-949.

33. Harmar AJ, Marston HM, Shen S, Spratt C, West KM, Sheward WJ, Morrison CF, Dorin JR, Piggins HD, Reubi JC, et al.: The VPAC(2) receptor is essential for circadian function in the mouse suprachiasmatic nuclei. Cell 2002, 109:497-508.

34. Aton SJ, Colwell CS, Harmar AJ, Waschek J, Herzog ED: Vasoactive intestinal polypeptide mediates circadian rhythmicity and synchrony in mammalian clock neurons. Nat Neurosci 2005 , 8:476-483.

35. Brown TM, Colwell CS, Waschek JA, Piggins HD: Disrupted neuronal activity rhythms in the suprachiasmatic nuclei of vasoactive intestinal polypeptide-deficient mice. J Neurophysiol 2007, 97:2553-2558.

36. Cutler DJ, Haraura M, Reed HE, Shen S, Sheward WJ, Morrison CF, Marston HM, Harmar AJ, Piggins HD: The mouse VPAC2 receptor confers suprachiasmatic nuclei cellular rhythmicity and responsiveness to vasoactive intestinal polypeptide in vitro. Eur J Neurosci 2003, 17:197-204.

37. Chaudhury D, Colwell CS: Circadian modulation of learning and memory in fear-conditioned mice. Behav Brain Res 2002, 133:95-108.

38. Lamont EW, Robinson B, Stewart J, Amir S: The central and basolateral nuclei of the amygdala exhibit opposite diurnal rhythms of expression of the clock protein Period2. Proc Nat Acad Sci USA 2005, 102:4180-4184

39. Wakamatsu H, Yoshinobu Y, Aida R, Moriya T, Akiyama M, Shibata S: Restricted-feeding-induced anticipatory activity rhythm is associated with a phase-shift of the expression of mPerl and mPer2 mRNA in the cerebral cortex and hippocampus but 
not in the suprachiasmatic nucleus of mice. Eur J Neurosci 200 I, 13:1190-1196.

40. Buijs RM, Wortel J, Hou YX: Colocalization of gamma-aminobutyric acid with vasopressin, vasoactive intestinal peptide, and somatostatin in the rat suprachiasmatic nucleus. J Comp Neurol 1995, 358:343-352.

41. Jinno S, Kosaka T: Patterns of expression of neuropeptides in GABAergic nonprincipal neurons in the mouse hippocampus: Quantitative analysis with optical disector. J Comp Neurol 2003, 461:333-349.

42. Magistretti PJ: VIP neurons in the cerebral cortex. Trends Pharmacol Sci 1990, II :250-254

43. Muller JF, Mascagni F, McDonald AJ: Synaptic connections of distinct interneuronal subpopulations in the rat basolateral amygdalar nucleus. J Comp Neurol 2003, 456:2 I7-236.

44. Waschek JA, Ellison J, Bravo DT, Handley V: Embryonic expression of vasoactive intestinal peptide (VIP) and VIP receptor genes. J Neurochem 1996, 66:1762-1765.

45. Hill JM, Lee SJ, Dibbern DA, Fridkin M, Gozes I, Brenneman DE: Pharmacologically distinct vasoactive intestinal peptide binding sites: CNS localization and role in embryonic growth. Neuroscience 1999, 93:783-791.

46. Waschek JA: Vasoactive intestinal peptide: an important trophic factor and developmental regulator? Dev Neurosci 1995, I7:1-7.

47. Moody TW, Hill JM, Jensen RT: VIP as a trophic factor in the CNS and cancer cells. Peptides 2003, 24:163-177.

48. Hill JM: Vasoactive intestinal peptide in neurodevelopmental disorders: therapeutic potential. Curr Pharm Des 2007, 13:1079-1089.

49. Vosko AM, Schroeder A, Loh DH, Colwell CS: Vasoactive intestinal peptide and the mammalian circadian system. Gen Comp Endocrinol 2007.

50. Maywood ES, Reddy AB, Wong GK, O'Neill JS, O'Brien JA, McMahon DG, Harmar AJ, Okamura H, Hastings MH: Synchronization and maintenance of timekeeping in suprachiasmatic circadian clock cells by neuropeptidergic signaling. Curr Biol 2006, 16:599-605

5I. Cain SW, Chou T, Ralph MR: Circadian modulation of performance on an aversion-based place learning task in hamsters. Behav Brain Res 2004, I50(I-2):20I-205.

52. Ralph MR, Ko CH, Antoniadis EA, Seco P, Irani F, Presta C, McDonald $\mathrm{RJ}$ : The significance of circadian phase for performance on a reward-based learning task in hamsters. Behav Brain Res 2002, 136(I):179-184.

53. Mistlberger RE, de Groot MH, Bossert JM, Marchant EG: Discrimination of circadian phase in intact and suprachiasmatic nuclei-ablated rats. Brain Res 1996, 739(I-2): 12-18.

54. Abe M, Herzog ED, Yamazaki S, Straume M, Tei H, Sakaki Y, Menaker $\mathrm{M}$, Block GD: Circadian rhythms in isolated brain regions. J Neurosci 2002, 22:350-356.

55. Yoo SH, Yamazaki S, Lowrey PL, Shimomura K, Ko CH, Buhr ED, Siepka SM, Hong HK, Oh WJ, Yoo OJ, et al:: PERIOD2::LUCIFERASE real-time reporting of circadian dynamics reveals persistent circadian oscillations in mouse peripheral tissues. Proc Natl Acad Sci USA 2004, 101:5339-5346.

56. Abraham U, Prior JL, Granados-Fuentes D, Piwnica-Worms DR, Herzog ED: Independent circadian oscillations of Period I in specific brain areas in vivo and in vitro. J Neurosci 2005, 25:8620-8626

57. Stratmann M, Schibler U: Properties, entrainment, and physiological functions of mammalian peripheral oscillators. J Bio Rhythms 2006, $21: 494-506$.

58. Kornmann B, Schaad O, Bujard H, Takahashi IS, Schibler U: Systemdriven and oscillator-dependent circadian transcription in mice with a conditionally active liver clock. PLoS Biol 2007, 5:e34.

59. Shearman LP, Zylka MJ, Weaver DR, Kolakowski LF, Reppert SM: Two period homologs: circadian expression and photic regulation in the suprachiasmatic nuclei. Neuron 1997 19:1261-1269.
Publish with Biomed Central and every scientist can read your work free of charge

"BioMed Central will be the most significant development for disseminating the results of biomedical research in our lifetime. "

Sir Paul Nurse, Cancer Research UK

Your research papers will be:

- available free of charge to the entire biomedical community

- peer reviewed and published immediately upon acceptance

- cited in PubMed and archived on PubMed Central

- yours - you keep the copyright
BioMedcentral 